\title{
COLETIVOS, OCUPAÇÕES E PROTESTOS SECUNDARISTAS: A FÊNIX, O LEÃO E A CRIANÇA
}

\author{
COLLECTIVES, OCCUPATIONS AND PROTESTS OF THE SECONDARY STUDENTS: \\ THE PHENIX, THE LION AND THE CHILD
}

COLECTIVOS, OCUPACIONES Y PROTESTAS SECUNDARISTAS:

EL FÉNIX, EL LEÓN Y LA NIÑEZ

Davis Moreira Alvim ${ }^{1}$

Alexsandro Rodrigues ${ }^{2}$

\section{RESUMO}

Pretende-se cartografarresistências secundaristas, indagando em que medida a construção da democracia, o aprendizado do comum e a conversação entre as diferenças podem ser suscitadas por resistências no campo educativo, especialmente na forma de coletivos, ocupações e protestos. Por meio do método cartográfico, busca-se encontrar campos de forças e potências das lutas, investigando a afirmatividade combativa e criativa das resistências. Demonstra-se que as lutas estudantis produzem contornos de um ensino, uma aprendizagem e uma convivência autônomos, envolvendo a construção de uma educação horizontal, prefigurando formas coletivas de liberdade e responsabilidade direcionadas pela horizontalidade de processos decisórios e ensaiando uma cultura educacional democrática.

PALAVRAS-CHAVE: Resistência à Escola. Movimento Estudantil. Contestação Estudantil. Democratização da Educação.

\section{ABSTRACT}

The intention is to cartography resistances of secondary students, asking how the construction of democracy, the learning of the common and the conversation between differences can be triggered by resistances in the educational field, especially in the form of collectives, occupations and protests. In accordance with the cartographic method, we sought to find the fields of forces and powers of the struggles, investigating the combative and creative aspects of resistances. We demonstrate that the struggles of the students produces outlines of an autonomous teaching, learning and coexisting, involving the construction of a horizontal education, prefiguring collective forms of freedom and responsibility directed by the horizontality of the process of decision-making and the rehearse of a democratic educational culture.

KEYWORDS: Resistance to oppression. Student movements. Protest movements. Democratization of education.

\footnotetext{
${ }^{1}$ Doutor em Filosofia - Pontifícia Universidade Católica de São Paulo (PUCSP). Professor de História do Instituto Federal de Educação, Ciência e Tecnologia do Espírito Santo (IFES) - Vitória , ES - Brasil . Email: davis.alvim@ifes.edu.br

${ }^{2}$ Professor da Universidade Federal do Espírito Santo (UFES). Professor do Programa de Pós-Graduação em Psicologia Institucional - Universidade Federal do Espírito Santo (UFES) - Vitória , ES. Email:

davisalvim@hotmail.com
}

(C) ETD-Educação Temática Digital Campinas, SP v.19 n.esp $\quad$ p.75-95 jan./mar. 2017 
RESUMEN

Se pretende cartografiarresistencias secundaristas, indagando enqué medida laconstrucción de la democracia, elaprendizajedelcomún y laconversación entre las diferencias pueden ser suscitadas por resistenciasenel campo educativo, especialmente en forma de colectivos, ocupaciones y protestas. Por mediodel método cartográfico, se busca encontrar campos de fuerzas y potencias de las luchas, investigando laafirmatividad combativa y creativa de lasresistencias. Se demuestra que las luchas de losestudiantesproducen contornos de una enseñanza, unaprendizaje y una convivencia autónomos, englobando laconstrucción de una educación horizontal, prefigurando formas colectivas de libertad y responsabilidaddireccionadas por lahorizontalidad de procesosdecisorios y ensayando una cultura educacional democrática.

PALABRAS CLAVE: Resistencia a laopresión. Movimientoestudiantil. Movimiento de protesta. Democratización de laeducación.

Primeira flor de junho (ORTELLADO, 2016), primavera secundarista (UBES, 2016), escolas de luta (CAMPOS; MEDEIROS; RIBEIRO, 2016), aula de cidadania (KÓKA, 2016), revolução secundarista (OLIVEIRA; PUERTA, 2016), anarquismo temporário (MOREIRA, 2015) ou, quem sabe, um dos gestos coletivos mais arrojados da história atual do Brasil (PELBART, 2016): essas são algumas das maneiras de expressar as potências das resistências secundaristas brasileiras. Nos últimos anos as ocupações escolares varreram o território nacional. Quase todos os estados da federação tiveram escolas ocupadas. São movimentos que se insurgem contra medidas governamentais - como o projeto de "reorganização escolar" no estado de São Paulo, a instituição do Novo Regime Fiscal (PEC 55/2016) ou a medida provisória de reforma do ensino médio (MP 746/2016) - mas tendem, ao mesmo tempo, a reivindicar melhorias nos processos educativos e experimentar novas formas de estar e aprender juntos. $O$ texto que se segue foi escrito em meio a um trabalho intenso em relação aos "ocupas": visitas, participação em redes de apoio, vigílias nas portas das escolas, realização de atividades com secundaristas e, enfim, entrega de alimentos e produtos de higiene, alguns sutilmente escorregados entre os portões em momentos de proibição policial.

As ocupações são parte de uma rede mais ampla de lutas secundaristas. Coletivos, movimentos e protestos têm se tornado experiências cada vez mais "virais" nos espaços escolares. São meninas que se movimentam contra a regulamentação de seus uniformes escolares dizendo "vai ter shortinho, sim!" ou "legaliza a legging!", meninos que usam shortinhos em apoio aos movimentos femininos, alunos e alunas que celebram o fim da distinção de gênero em seus uniformes, protestos pelos direitos das minorias, cartazes colados nas paredes, coletivos que experimentam relações horizontais e movimentos que denunciam opressõesperpetradas no ambiente escolar. Trata-se de confrontar medidas administrativas e, simultaneamente, criar outras formas de estar e lutar nas escolas por

(C) ETD-Educação Temática Digital Campinas, SP v.19 n.esp $\quad$ p.75-95 jan./mar. 2017 
meio do diálogo com movimentos sociais, rodas de conversa, arraiais de ocupação, cineclubes, formação de coletivos, produção de curtas-metragens, ocupações de recreios, composição de músicas, organização de rádios escolares e, ainda, grupos de dança, teatro e poesia.

Nossa proposta é cartografar ${ }^{3}$ resistências secundaristas, indagando em que medida a construção da democracia, o aprendizado do comum ${ }^{4}$ e a conversação entre as diferenças podem ser suscitadas por operações de resistência no campo educativo, especialmente na forma de coletivos, ocupações e protestos. Pretendemos desdobrar aquilo que as lutas secundaristas comportam em termos de potência inventiva, "ainda que de modo balbuciante ou embrionário, de novo, de inaugural, de fundante" (Pelbart, 2016). Nesse sentido, desejamos compreender em que medida as lutas dos estudantes produzem contornos de processos educativos e convivências mais autônomos, envolvendo possibilidades da construção de uma educação horizontal. Para tanto, encontraremos mais de perto o movimento "Vai ter shortinho, sim!", organizado por estudantes do Colégio Anchieta em Porto Alegre - RS, as experiências dos coletivos Feminifes, Colorifes, Melanina e Icacheou, formados no contexto das lutas estudantis no Instituto Federal do Espírito Santo (Ifes) em Linhares - ES, o Cineclube Nome Provisório e o Movimento Fala Boca, que emergiram na Escola Irmã Maria Horta, em Vitória - ES; além de algumas experiências dispersas entre os recentes movimentos das ocupações brasileiras.

Mas o que entendemos por resistência? Diante de poderes que submetem e oprimem, invariavelmente, operam resistências. Judith Revel (2012) se aproximou da noção de resistência com o objetivo de compreender as lutas que possibilitam o rompimento com "o círculo dialético que transforma insidiosamente todo contrapoder em um outro poder" (REVEL, 2012, p. 107), evitando defini-la como um mero hiato de libertação, necessariamente reabsorvido pelas relações de poder ou, ainda, como simples reações

\footnotetext{
${ }^{3}$ O método cartográfico se opõe à busca das regularidades, procurando, diferentemente, encontrar campos de forças e potências, preferindo os movimentos às posições fixas. Apontam-se linhas de fuga, rupturas, fraturas e criações. Trata-se de investigar a afirmatividade combativa e criativa das resistências. Cartografam-se resistências que operam como linhas ou vetores entrelaçados e, em certa medida, diferentes das relações de poder, pois lutam de forma ativa e afirmativa, em um movimento que não acompanha mecanicamente as oscilações do poder (RODRIGUES; ALVIM, 2016).

${ }^{4}$ Por comum (common) entende-se não apenas os bens já dados pelo mundo material, como o ar, a água ou os frutos do solo, mas principalmente os resultados da produção social que são necessários à interação e à produção, tais como conhecimentos, linguagens, informações, afetos, imagens, entre outros (HARDT; NEGRI, 2016). O comum está assim relacionado aos resultados da criatividade e do trabalho colaborativo e autônomo das multidões em luta (HARDT, 2010).
}

(C) ETD-Educação Temática Digital Campinas, SP v.19 n.esp $\quad$ p.75-95 jan./mar. 2017 
invertidas ou especulares. Forças que operam na negatividade - sob as formas da supressão e do aniquilamento - não podem ser chamadas de resistências que, por sua vez, funcionam sobretudo no terreno mais difícil, raro e pleno da positividade e da afirmação.

Gilles Deleuze (1996), sintetizando suas colaborações com Félix Guattari, sugere que nas ações resistentes não predominam a conservação, a permanência, a imobilidade ou a oposição ao movimento. O poder não é o responsável pela ação constituinte, uma vez que há certo primado das resistências sobre as relações de poder, que são formações secundárias, ou melhor, reterritorializações. Dessa forma, Deleuze e Guattari nos possibilitam pensar as resistências como fluxos capazes fazer o mundo fugir em direção a outros mundos possíveis, de tal maneira que não podem ser tomadas apenas como enfrentamentos fragmentários ou focos de luta contra os mecanismos de poder (RODRIGUES; ALVIM, 2016).

Algumas formulações de Michel Foucault (2006) ressaltam o aspecto produtivo das relações de poder e aparentam dar certa ênfase ao aspecto opositor das resistências sob o papel "de adversário, de alvo, de apoio, de saliência que permite apreensão" (FOUCAULT, 2006, p. 106), ou seja, um funcionamento que tende à participação no jogo do poder. Contudo, progressivamente, o filósofo passou a destacar o aspecto criativo das resistências, entendidas sobretudo como força criadora de vidas, prazeres, amizades, éticas e políticas. Nesse sentido, a "resistência vem em primeiro lugar, e ela fica superior a todas as forças do processo" (FOUCAULT, 2014, p. 257), passando a ser uma palavra-chave na dinâmica das relações de poder.

Michael Hardt e Antonio Negri (2016) concordam que não se deve pensar as relações de poder como primordiais e as resistências como simples reações a elas. Se o poder se exerce sobre sujeitos livres é importante ressaltar que não só a liberdade é anterior a ele como, mais importante, as resistências operam esforços "para fomentar, expandir e fortalecer essa liberdade" (HARDT; NEGRI, 2016, p. 99). Resistência e liberdade constantemente ultrapassam as relações de dominação e, por isso, comportam potências para liberar novas forças criativas que vão além da simples oposição.

As forças resistentes, portanto, são sempre duplas: são combativas, uma vez que enfrentam e recusam determinadas relações de poder, mas sobretudo criativas, já que incessantemente propõem, de forma autônoma, a reorganização das relações sociais, não somente desafiando as normas instituídas, como também propondo novas formas de convívio, amor e de maquinação do comum. Nômades, as resistências envolvem, a um só

(C) ETD-Educação Temática Digital Campinas, SP v.19 n.esp $\quad$ p.75-95 jan./mar. 2017 
tempo, o confronto, a conexão em rede e os fluxos de invenção autônoma capazes de transformar, por exemplo, "os procedimentos que utilizamos habitualmente ao designar o que pode/não pode ser feito, o que é aprender, o que é ensinar, o que é participar" (HECKERT, 2004, p. 156).

A máquina escolar não está livre do atravessamento reativo do poder e nem das ações resistentes. Nela opera a produção de uma subjetividade sujeitada e reativa que tende a fechar ou controlar as possibilidades de liberdade e criatividade. A naturalização de hierarquias, as micropenalidades (como a ocorrência, as suspensões ou as transferências), a atribuição de notas, a obrigatoriedade da presença ou do silêncio e a obediência ao comando sonoro do sinal não são simples resquícios do passado, mas um jogo binário de negatividades e positividades voltados para a organização, reativação, conservação e efetivação das relações capitalistas pelas capilaridades sociais (CARVALHO; CAMARGO, 2015).

O aparelho escolarizador arranja um espaço de circulação de discriminações de diversas ordens, como o etarismo, o racismo, o machismo, a LGBTfobia e tantas outras formas de normalização. Para Rogério Diniz Junqueira (2014) tais opressões não são elementos intrusos ou marginais, antes, são "elementos estruturantes do espaço escolar, onde são cotidiana e sistematicamente consentidos, cultivados e ensinados, produzindo efeitos sobre todos/as" (JUNQUEIRA, 2014, p. 101). É uma "pedagogia do insulto" que opera por meio de ações preconceituosas, medidas discriminatórias, constrangimentos, ameaças, ridicularizações, agressões físicas e medidas desumanizantes, constantes na cotidianidade escolar.

Paralelamente, porém, fluem problematizações e conexões que podem curtocircuitar a máquina escolar, instigando e convocando o pensamento a agir, ativando rupturas, atopias e engendrando novas experiências. A recusa a se submeter à disciplina escolar, a negação da coisificação de si e a produção de relações horizontais, por exemplo, fazem "oscilar, rachar, o caráter de totalização de uma instituição" (GUATTARI, 2004, p. 69), produzindo uma miríade de pequenas máquinas que, por meio da sabotagem criativa, esboçam sintomas da afirmação de outros mundos possíveis, da inserção e ação nos coletivos e, enfim, de cortes no sono dogmático da educação formal (CARVALHO; CAMARGO, 2015). Diante da profusão atual das lutas secundaristas, talvez estejamos em condição de precipitar "relações experimentais e libertárias, em que ensinar e aprender sejam aventuras do pensamento" (GALLO; FIGUEIREDO, 2015, p. 48) e de operar

(C) ETD- Educação Temática Digital Campinas, SP v.19 n.esp $\quad$ p. 75-95 jan./mar. 2017 
inventividades. Às micromáquinas de curto-circuito, às operações inventivas e autônomas, uma linha de força se oferece: a linha das resistências secundaristas.

Uma das micromáquinas resistentes que se alastrou pelas escolas brasileiras foi a luta contra a desigualdade de gênero relacionada aos uniformes. Ganhou destaque nas redes sociais e na grande mídia o movimento "Vai ter shortinho, sim!", organizado pelas alunas do Colégio Anchieta, na cidade de Porto Alegre. As alunas relatam que se insurgiram contra o posicionamento da instituição que não apenas proibiu o uso de shorts, mas fez uso de justificativas machistas para legitimar a interdição. Uma delas conta que "eles abordavam a menina falando que, se ela não trocasse de roupa, teria que sair da aula e ir para casa porque sua roupa poderia 'causar acidentes' e 'distrair os alunos e professores'”5 5 . O movimento operou três ações coordenadas: primeiro, a criação de um grupo de discussão virtual (com cerca de 300 alunas) que rapidamente levou à criação da página "Vai ter shortinhos, sim!" no Facebook (hoje com mais de 20.000 curtidas); segundo, a criação de um abaixo-assinado "que em poucas horas recebeu mais de 3 mil assinaturas" ${ }^{6}$; e, enfim, um protesto na hora do recreio da escola no qualas meninas usaram camisas pretas e shortinhos.

Disponível no site Change.org (2016), a petição do movimento é um verdadeiro tratado político e pedagógico. Nela se denunciam as opressões da escola que, com a regulamentação do uniforme, reforçam o poder masculino, promovendo a ideia de que assediar é da natureza dos homens, culpabilizando as mulheres e colocando sobre elas a responsabilidade de evitar o assédio. $O$ texto problematiza também o modelo de educação tecnicista que visa o treinamento para a prova do Exame Nacional do Ensino Médio (Enem) e reivindica a importância do que chama de "educação social e política". Com essa expressão, as alunas manifestam seu anseio por uma educação que combata violências e, assim, criar um mundo em que as mulheres sejam respeitadas sem imposições estéticas sobre seus corpos e comportamentos, nem julgamentos sobre sua sexualidade. Promover "educação social e política" que debata a legalização das drogas e do aborto para que cesse a aniquilação das incontáveis vidas perdidas na guerra contra o tráfico e nos procedimentos abortivos ilegais; criar um mundo em que os cotistas também sejam tratados com respeito e exista laicidade na política. Enfim, que o capital não seja mais importante que a vida.

\footnotetext{
${ }^{5}$ Relato enviado por participante do movimento "Vai ter shortinho, sim!". Relato 1[13 set. 2016, 20:27] Porto Alegre. Messenger.

${ }^{6}$ Ibid.
}

(C) ETD- Educação Temática Digital Campinas, SP v.19 n.esp $\quad$ p. 75-95 jan./mar. 2017 
Embora não tenha tido êxito na mudança da regulamentação do uniforme do Colégio Anchieta, o movimento se conectou com outras resistências estudantis, suscitando ressonâncias onde menos se poderia esperar. Por exemplo, no Colégio Sinodal, em São Leopoldo, no Vale do Sinos, meninas e meninos, usando shortinhos, realizaram um protesto de apoio ao movimento (VASCONCELLOS, 2016). Enquanto isso, meninas do Colégio Etapa, em São Paulo, aderiram ao movimento promovendo uma síntese das táticas utilizadas nos colégios Anchieta e Sinodal: a criação de uma página no Facebook, a petição on-line (com mais de 4.000 assinaturas), o protesto com cartazes e o apoio dos meninos - que subiram a bainha de suas bermudas para ficarem mais curtas (AGUIAR, 2016). Dessa vez, houve sucesso na mudança da regulamentação do uniforme.

No Instituto Federal do Espírito Santo, em Linhares, a regulamentação do uniforme também precipitou resistências. Uma delas veio com o coletivo Feminifes que, desde sua criação, se colocou "contra o silenciamento, o submetimento e a opressão das mulheres" (FEMINIFES, 2016) e procurou organizar uma agenda pública com ações em faculdades locais e em cursos de extensão. No verão de 2015, uma nova regulamentação de uniforme proibiu as alunas da instituição de utilizarem short, bermuda e calça legging, adotando a calça jeans como única vestimenta regular permitida. As alunas do coletivo realizaram um protesto colando cartazes nas paredes da escola e reivindicando a "legalização da legging". A história de luta do Feminifes guarda similaridades e diferenças com o movimento "Vai ter shortinho, sim!". Também começou como "um grupo para comentar coisas entre meninas feministas" e "acabou se tornando o local de manifesto de várias revoltas por conta de situações de violência vivenciadas por nós" ${ }^{8}$. Também teve como ponto de intensificação de suas ações a regulamentação do uniforme e as falas consideradas machistas na tentativa institucional de explicar a desigualdade de gênero nas roupas: "em especial, protestávamos contra a proibição da legging, visto que a justificativa para tal proibição era de um machismo absurdo" ${ }^{9}$.

Diferente do "Vai ter shortinho, sim!", o Feminifes encontrou uma reação avaliada como agressiva por parte de setores da escola. Uma das participantes do coletivo contou que havia alunos dizendo "palavras de ódio nos corredores" ${ }^{10}$ e "professores nos criticando em sala de aula"11. Algumas participantes relataram ainda que saíam das aulas para chorar

\footnotetext{
${ }^{7}$ Relato enviado por participante do Coletivo Feminifes. Relato 2 [14 set. 2016, 23:32] Linhares. WhatsApp.

8 Ibid.

${ }^{9}$ Ibid.

${ }^{10}$ Ibid.

11 Ibid.
}

(C) ETD-Educação Temática Digital Campinas, SP v.19 n.esp $\quad$ p.75-95 jan./mar. 2017 
mediante os comentários de alguns docentes e alunos: "naquela semana que os cartazes estavam colados, chorei todos os dias" ${ }^{12}$. Em resposta ao machismo institucional, alguns alunos e alunas escreveram de batom nos espelhos dos banheiros femininos frases de empoderamento (você é linda!) e no banheiro masculino frases contra o machismo (machistas não passarão!). O episódio dos espelhos acabou gerando mais reações negativas contra as mulheres do coletivo.

A resposta das secundaristas feministas foi intensificar sua auto-organização. Em suas redes sociais publicaram fotos de outros escritos nos banheiros, ignorados pelos críticos, e sugeriram que a preocupação com o batom nos espelhos era seletivamente machista. Afirmaram ainda que, apesar das escritas no banheiro não serem deliberação do coletivo, se colocavam firmemente em apoio às alunas perseguidas pelo ato. Em seguida, na realização do $V$ Seminário de Humanidades, reivindicaram que a comissão de organização trouxesse ao campus feministas para realizar oficinas, minicursos e palestras. A prova do Enem de 2015 - que exigiu conhecimentos sobre feminismo na prova de Ciências Humanas e sobre violência contra a mulher na redação - acabou dando mais força ao coletivo e inibindo discursos que diziam que a escola não era lugar para debate sobre gênero e sexualidade. Apesar - ou por causa - dos conflitos, o campus do Ifes revogou a portaria de uniforme, que foi reformulada, permitindo o uso da calça legging.

O movimento das alunas do Ifes resultou em uma presença importante do coletivo no ambiente escolar, passando, inclusive, a ser referência e presença constante nos debates sobre feminismo em outras escolas de ensino médio e superior do norte do estado. A autoorganização feminina serviu ainda de exemplo para que outras minorias também se organizassem, surgindo em seguida o Colorifes, um coletivo de alunos e alunas LGBT, além do Icacheou e o Coletivo Melanina, voltados para as questões étnico-raciais.

Entre as muitas potências advindas da participação nos coletivos da escola, alunas e alunos ressaltaram o apoio mútuo quando o "professor veio me perguntar o que as feministas achavam disso (como sempre faz) e aí outras meninas responderam no meu lugar"13, a percepção de agora ter "capacidade de falar o que eu penso em público sem medo e melhor também"14, o empoderamento para "me sentir negra, gorda e bonita,

\footnotetext{
12 Ibid.

${ }^{13}$ Entrevista coletiva com participantes dos coletivos Colorifes, Coletivo Melanina e Icacheou. Entrevista 1 [20 set. 2016] Linhares. Arquivo de mp3. 01h 32min 18s.

${ }^{14}$ Ibid.
}

(C) ETD-Educação Temática Digital Campinas, SP v.19 n.esp $\quad$ p.75-95 jan./mar. 2017 
porque o Ifes trouxe um balde cheio de amor próprio pra $\operatorname{mim}^{15}$, a criação de "um interesse mais forte pela política e pelas coisas da coletividade" ${ }^{16}$, além do fim do desejo de "matar o gay dentro de $\mathrm{mim}^{\prime 17}$. Mesmo o processo de dor, advindo da escrita nos espelhos, fez uma aluna achar "força no desespero: encontrei a mim mesma enfrentando as violências que sofri porque escrevi nos espelhos" ${ }^{18}$.

A escola Irmã Maria Horta, localizada em Vitória, também vivenciou uma profusão de resistências entre seus muros. Entre elas se destacam o Cineclube Nome Provisório e o Movimento Fala Boca. O cineclube foi criado em 2012 com o desejo explícito de deslocar as coisas e fazer oscilar o espaço escolar "com o propósito de exibir, transmitir e espalhar coisas maravilhosas pro público" (CINECLUBE NOME PROVISÓRIO, 2016). Em seguida, como uma espécie de desdobramento das atividades do cineclube, surgiu também o Movimento Fala Boca, que buscava combater o que chamaram em sua página do Facebook (2016) de "um cenário silenciador e repleto de opressões cotidianas" por meio de manifestações culturais, artísticas e denúncias que visavam demonstrar o mal-estar dos e das estudantes com o cotidiano escolar.

Os encontros com o Cineclube Nome Provisório são marcados por abraços e partilha de carinhos. Uma presença no ar expressa uma história de luta e também de dor. O termo "acolhimento" é repetido inúmeras vezes nas narrativas para descrever a experiência de participar do cineclube pela primeira vez. No decorrer das conversas a palavra aparece em seu significado pleno: trata-se da experiência de "construir relações mais horizontais"19, onde a fala seja partilhada e respeitada por todos e todas e as hierarquias que marcam o aparato escolar sejam questionadas. Não se trata apenas de exibir e debater filmes, mas de, conscientemente, construir novas relações e outras maneiras de existir: "a criação de horizontalidade é um desejo nosso" ${ }^{20}$. O cineclube é um local onde secundaristas conseguiam se sentir bem na escola, de resto marcada por uma lógica que thes era hostil com os sinais, as chamadas, as notas e as avaliações. Uma das participantes considerava a

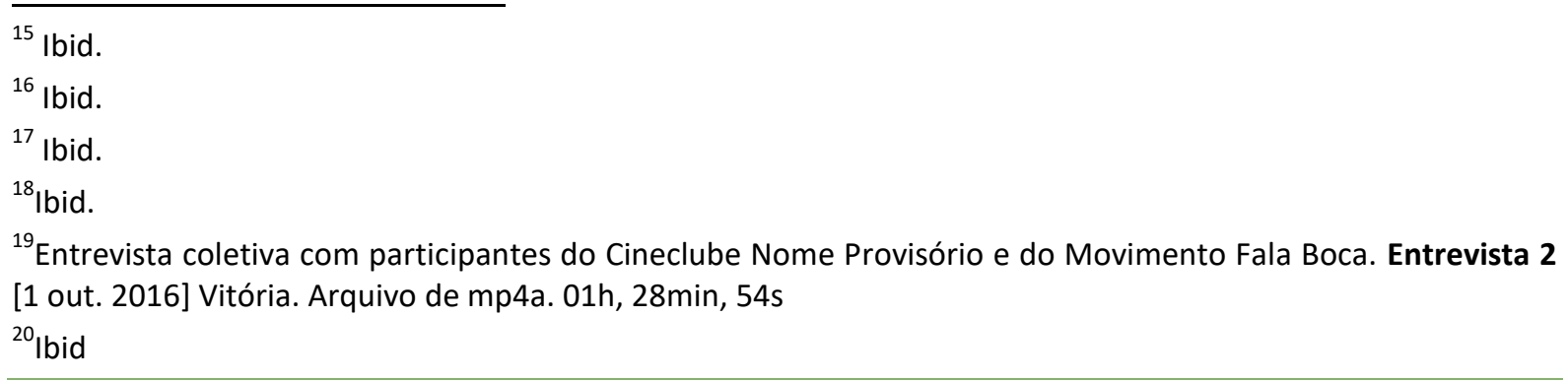

(C) ETD-Educação Temática Digital Campinas, SP v.19 n.esp $\quad$ p.75-95 jan./mar. 2017 
ação da coordenação escolar autoritária e racista enquanto, por oposição, nos encontros do Cineclube Nome Provisório sentiu-se "acolhida em um espaço que não me adoece"21.

O cineclube é entendido como um lugar de intermezzo, um espaço híbrido que não pertence completamente à escola mas, ao mesmo tempo, não está completamente fora dela. Segundo um dos participantes, trata-se de "usar de forma estratégica o espaço institucional" ${ }^{22}$ para "'afetizar' as relações" ${ }^{23}$. O cineclube é "da escola", quando é necessário fazer uso do aparato institucional mas, na verdade, apenas ocorre "na escola", pois privilegia sua autonomia em relação ao dispositivo disciplinar escolar. "Não queríamos ser um braço pedagógico da escola" ${ }^{24}$, explica um dos participantes do coletivo. A horizontalidade confunde as pressuposições hierárquicas de diretores/as, professores/as e mesmo de pesquisadores/as que insistem, de maneira equivocada, em entender que "o professor coordenador" (CAZÉ, 2015. p. 84) estava (ou não) presente nas sessões cineclubistas, sem notar, contudo, que são todos e todas coordenadores - ou, melhor ainda, que não há coordenadores/as.

Entre as principais potências despertadas pela experimentação no coletivo foram citados o prazer de colorir o cinza da escola caminhando pelos corredores com os rostos pintados, "perturbando o cotidiano da escola" ${ }^{25}$ com cantos coletivos que repetiam "o cineclube vem aí! o cineclube vem aí!" ${ }^{26}$ e o sentimento de autonomia ao realizar sessões sem a presença de professores. Um dos relatos que mais nos chamou a atenção veio de um participante que contou ter criado uma nova relação com a educação em quenão é mais o professor quem conduz e planeja as ações de forma centralizada, sendo de responsabilidade estudantil programar e administrar atividades, como escolher os filmes, organizar os debates, fazer inscrição em editais de fomento e calcular o tempo adequado do evento. "O professor não pode ser colocado num pedestal” ${ }^{27}$, resumiu.

Como um desdobramento das atividades do cineclube surgiu, na mesma escola, o Movimento Fala Boca. Por meio de uma dinâmica de ocupações de recreios, o movimento teve por objetivo a crítica das opressões praticadas no cotidiano escolar. Para isso, produziu

\footnotetext{
${ }^{21} \mathrm{Ibid}$.

22 Ibid.

${ }^{23}$ Ibid.

${ }^{24}$ Ibid.

${ }^{25} \mathrm{Ibid}$.

${ }^{26}$ Ibid.

${ }^{27}$ Ibid.
}

(C) ETD-Educação Temática Digital Campinas, SP v.19 n.esp $\quad$ p.75-95 jan./mar. 2017 
um curta-metragem, disponível no YouTube (2016), chamado "Escola sem opressão Movimento Fala Boca", que inicia com um grupo de alunos e alunas repetindo a frase "escola sem opressão! escola sem opressão!" e em seguida anuncia: "não aceitaremos mais: desmandos, autoritarismos, machismos, racismos e homofobias dentro da escola". Um projeto é colocado pelo curta-metragem: uma escola que respeite a pluralidade de subjetividades discentes e que garanta o exercício da autonomia, uma escola "sem opressões, plural, sensível, horizontal, libertária e mais humana".

O aparelho escolar tensionou ao limite quando o movimento organizou um evento com a temática "Qual escola não queremos? Quais escolas queremos?", em queestudantes fizeram uso do microfone para comentar situações de opressão que viviam no cotidiano escolar e houve o que se entendeu como um "boicote por parte da coordenação da escola" ${ }^{28}$ que, em seguida, levou à decisão administrativa de encerrar as atividades do cineclube sob a justificativa de que suas ações ameaçavam "a paz no espaço escolar" 29 . 0 Cineclube Nome Provisório e o Movimento Fala Boca foram impedidos de funcionar na escola, que deliberou pelo fim das atividades de ocupação do recreio e instaurou um processo administrativo contra o professor que integrava as ações junto com o grupo.

A ação resistente dos secundaristas poderia ter se encerrado com o remanejamento de sala ou de turno de estudantes vinculados ao Cineclube Nome Provisório e ao Fala Boca, com o processo administrativo contra o professor, com a proliferação de "tratamento docente indiferente e ou ríspido aos discentes envolvidos" ${ }^{\prime 30}$ ou com a proibição da continuidade das atividades desses movimentos. Porém, o cineclube continuou operando de forma intensa em outras escolas, em espaços educativos não formais e participando ativamente da vida cultural e política do Espírito Santo. No momento em que escrevemos, um desfecho potente e irônico aconteceu: o colégio Irmã Maria Horta - o mesmo que coibiu as atividades dos movimentos - foi ocupado e, em seu primeiro cronograma de atividades, a página Ocupa Irmã Maria Horta (2016) no Facebook anunciou: "19:00h - exibição do Cineclube Nome Provisório".

\footnotetext{
${ }^{28}$ CINEBLUBE NOME PROVISÓRIO. Nascer: sob os olhos de quem nascemos? Narrativas tecidas do tempo Fala Boca do Cineclube Nome Provisório [texto não publicado que narra a história do Cineclube Nome Provisório e do movimento Fala Boca, gentilmente cedido pelo coletivo], 2016. Cf. também a nota de repúdio escrita pelo movimento disponível em: <https://www.facebook.com/cinenomeprovisorio/posts/1036878006404951>

${ }^{29}$ CINEBLUBE NOME PROVISÓRIO. Nascer: sob os olhos de quem nascemos? Narrativas tecidas do tempo Fala Boca do Cineclube Nome Provisório [texto não publicado que narra a história do Cineclube Nome Provisório e do movimento Fala Boca, gentilmente cedido pelo coletivo], 2016. ${ }^{30} \mathrm{lbid}$.
}

(C) ETD-Educação Temática Digital Campinas, SP v.19 n.esp $\quad$ p.75-95 jan./mar. 2017 
A partir de outubro de 2016 o Espírito Santo foi surpreendido por uma onda de resistências que contou com mais de 50 escolas ocupadas em cerca de duas semanas. A disseminação dos "ocupas" não estava desconectada da rede de resistências secundaristas que já operava por meio de protestos, movimentos, coletivos e até mesmo tentativas abortadas de auto-organização que vinham fazendo a geografia escolar oscilar. Nesse sentido, além de se insurgirem contra medidas governamentais, as ocupações não deixavam de comportar revoltas contra as relações de poder que impedem, regulam e desestimulam os processos de resistência discentes, durante o período regular das aulas.

Em algumas escolas, ocupantes improvisaram um jogo de inversão disciplinar, fazendo com que os profissionais da educação sentissem na pele as opressões que estudantes vivenciam continuamente nos colégios. Um integrante do coletivo $\mathrm{O}$ Mal Educado narra que, no colégio Heloisa de Assumpção, em Osasco-SP, depois de ter tentado retirar as faixas da ocupação no dia anterior, a diretora retornou à escola e escutou da comissão de segurança da ocupação que "hoje vocês não entram, chegaram atrasados. 0 sinal já bateu" (apudCAMPOS; MEDEIROS; RIBEIRO, 2016, p.90). No mesmo sentido, no colégio Irmã Maria Horta, em Vitória, um professor tentou entrar na escola durante a ocupação e foi impedido. O docente argumentou que a ocupação estava impedindo seu direito de ir e vir. Imediatamente, um dos estudantes responsáveis pela segurança do portão rebateu: "tipo do mesmo jeito que você me proíbe de beber água, ir no banheiro e entrar durante as suas aulas?" (informação verbal) ${ }^{31}$.

Para além da simples inversão das opressões escolares, as ocupações ajudam a experimentar uma escola mais democrática, horizontal e prazerosa (CAMPOS; MEDEIROS; RIBEIRO, 2016). Em Vitória visitamos a ocupação da escola EEEFM Maria Ortiz para um estudo coletivo do projeto de lei Escola sem Partido (PL 193/2016). Fomos recebidos por uma comissão de segurança predominantemente feminina. Uma das alunas nos levou para conhecer a escola ocupada. Ela nos apresentou as salas de aula, a cozinha e a sacada do colégio com sua bela vista para o porto de Vitória. Tudo estava impecavelmente limpo e organizado. Em seguida fomos conduzidos para a sala onde ocorreria a atividade. Ainda estava acontecendo uma roda de conversa sobre gênero e violência contra a mulher em que

\footnotetext{
${ }^{31}$ As informações e diálogos relacionados às ocupações capixabas provêm diretamente dos acontecimentos que presenciamos no trabalho da Rede de Apoio às Ocupações Capixabas e nas atividades oferecidas nas escolas ocupadas. Não realizamos entrevistas formais ou gravação dessas atividades, com exceção da roda de conversa realizada na Escola EEEFM Aristóbulo Barbosa Leão, gravada por iniciativa dos e das ocupantes que, gentilmente, nos concederam o arquivo.
}

(C) ETD-Educação Temática Digital Campinas, SP v.19 n.esp $\quad$ p.75-95 jan./mar. 2017 
alunas e alunos relatavam casos de machismo no ambiente escolar e familiar. Alguns secundaristas nos perguntaram qual seria o tema a ser trabalhado e respondemos "Escola sem Partido, a popular 'Lei da Mordaça'” e parte da sala comemorou animada.

Durante a leitura do projeto de lei, um dos trechos que mais provocou indignação foi o que diz respeito ao "direito dos pais a que seus filhos recebam a educação religiosa e moral que esteja de acordo com as suas próprias conviç̧ões" (BRASIL. Projeto de Lei do Senado no 193, 2016, Art. 20). Reagindo ao artigo da lei, alguns problemas com as famílias foram ressaltados. Um secundarista se declarou portador de autismo leve e relatou que seus pais haviam tratado sua condição como indício de possessão demoníaca durante grande parte da sua infância. De forma emocionada, contou sobre seu processo de autocontrole da doença feito de forma solitária e autônoma - sem ajuda médica. O tema das roupas femininas retornou quando uma estudante disse que, desde que passou a usar shortinhos, sua mãe a proibiu de sair de casa e convocou amigas para rezarem contra o demônio que estaria em seu corpo. Houve ainda indignação geral com o projeto por sua preocupação em punir professores que estimulam estudantes a participarem de manifestações, mas negligencia casos em queo docente diz, por exemplo, que uma mulher de short curto está pedindo para ser estuprada.

Já cansados do trabalho exaustivo nas redes de apoio às ocupações capixabas, fomos convidados para fazer um "aulão para o Enem" na ocupação da Escola EEEFM Aristóbulo Barbosa Leão, na Serra. Embora hostis ao modelo do chamado "aulão", acatamos o desafio. Quando chegamos ao colégio encontramos um grupo de estudantes esgotados devido aos três "aulões" seguidos que haviam assistido. Em conversa com os e as ocupantes decidimos mudar a proposta para uma roda de conversa no refeitório da escola. Iniciamos a atividade falando sobre nossa experiência nas visitas às outras ocupações, relatando o que havíamos visto e aprendido. Rapidamente um conjunto de narrativas tocantes se fez.

Um dos ocupantes achou curioso o espanto de um professor com a quantidade de estudantes, tidos como indisciplinados e problemáticos pelo corpo escolar que, porém, se engajavam cumprindo as regras coletivas e participando, ativamente, das aulas promovidas no "ocupa". Insinuou-se ainda que a ocupação dilui as individualidades e reforça a lógica coletiva por meio das assembleias, da aproximação entre estudantes que antes se hostilizavam e do suporte em momentos difíceis: "a gente quer saber como o outro está, isso é magico!"32, exclamou uma ocupante. Os ocupantes também ressaltaram mudanças na

\footnotetext{
${ }^{32}$ Roda de conversa feita com participantes do Ocupa ABL. Roda de conversa 1 [3 nov. 2016] Vitória. Arquivo de mp4a. $55 \mathrm{~min}, 54 \mathrm{~s}$
}

(C) ETD-Educação Temática Digital Campinas, SP v.19 n.esp $\quad$ p.75-95 jan./mar. 2017 
relação com seus pais. Em alguns casos contou-se que, a princípio, os pais reprovavam as ocupações mas que, com o tempo, alguns entenderam o movimento. Um deles ressaltou que foi dormir em casa um dia e sua mãe o chamou logo cedo: "acorda menino, você não vai pra ocupação?"33.

Na mesma ocasião, uma aluna ressaltou que as atividades nos "ocupas" são mais interessantes do que as aulas regulares em quealunos e alunas são obrigados a "escutar, ficar quieto e fazer o dever" ${ }^{34}$. Na ocupação, ao contrário, "é tudo muito diferente" ${ }^{35}$, pois "você não é aquela coisa de copista, você não precisa copiar porque está aprendendo" ${ }^{36}$. Outro estudante complementou ainda que "o mais legal é que quem está organizando isso tudo é a gente" ${ }^{37}$. Um ocupante evangélico explicou que conviveu com um grupo de amigos que odeiam homossexuais, que abominam o contato, dizendo que, agora, dorme lado a lado com seu novo amigo gay e jamais irá permitir novamente que falem ou tratem LGBT dessa forma: "pô véio, são irmãos, são irmãs, como a gente pode querer distância? (...) eu tô saindo daqui uma pessoa nova, uma pessoa transformada" ${ }^{38}$. Enfim, outro ocupante concluiu: "a gente poderia ser visto como uma fênix, porque quando nossos preconceitos chegam aqui eles morrem e nós renascemos pessoas renovadas" ${ }^{39}$. Ao final, aconteceu um abraço coletivo, embalado pelo já clássico canto dos secundaristas ocupados: "ocupar e resistir! ocupar e resistir! ocupar e resistir!".

Embora as resistências secundaristas possuam suas singularidades, em linhas gerais pode-se indicar elementos comuns. Entre os coletivos e as ocupações ressaltou-se que as atividades diversificadas e dinâmicas estimulam a aprendizagem, sendo indicadas como mais produtivas e prazerosas que o excesso de aulas expositivas, a repetição dos exercícios e as cópias de trabalhos no quadro. Os estudantes se veem empolgados diante do desafio de se auto-organizar, criando, por exemplo, programações de atividades, marcando e realizando reuniões entre si ou com a administração da escola e gerindo coletivamente páginas na internet. Coletivos, ocupações e protestos tendem ainda a produzir um espaço

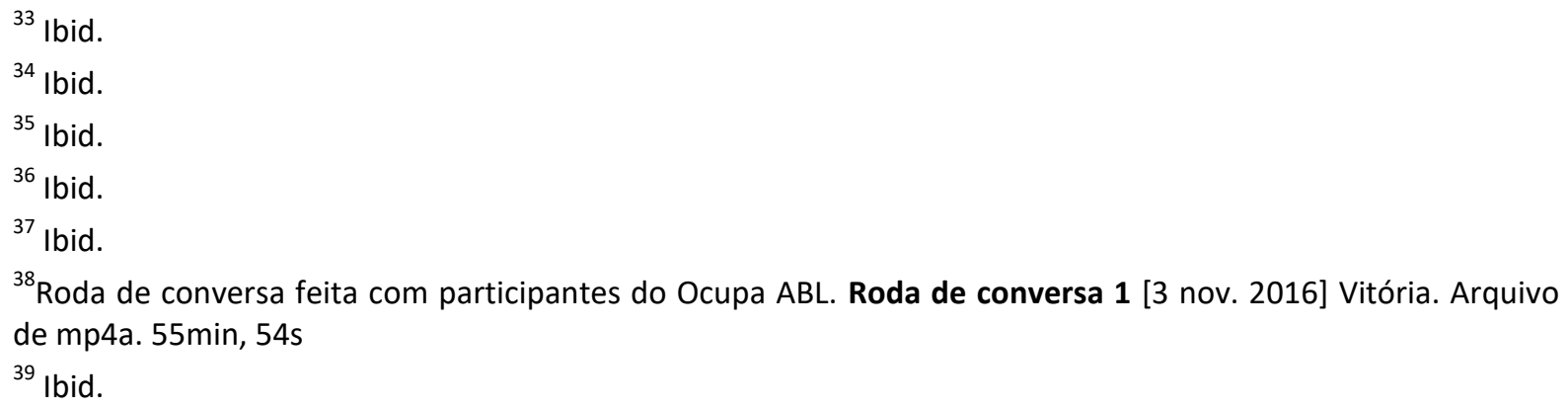

(C) ETD-Educação Temática Digital Campinas, SP v.19 n.esp $\quad$ p.75-95 jan./mar. 2017 
comum entre estudantes de diferentes turmas, turnos e grupos de afinidade, antes divididos e esquadrinhados pela lógica espacial e temporal disciplinar da escola.

Estamos vivenciando um processo de resistências, no sentido forte do termo. São movimentos contra as discriminações, as abordagens tendenciosas das mídias tradicionais, a centralização administrativa das escolas, a mercantilização da educação ea certas propostas de lei governamentais. Ao mesmo tempo são resistências inventivas, que delineiam um espaço de experimentação educacional e político, configurando uma alternativa real ao que está dado no campo da política representativa e das escolas disciplinares. Os secundaristas desenham uma contínua renovação de ações criativas e constituintes (MENDES, 2015) e inventam sociabilidades que levam à reapropriação do espaço disciplinar e normalizador da escola.

Trata-se da pré-figuração de formas coletivas de liberdade e responsabilidade direcionadas pela busca da horizontalidade de processos decisórios, pela inexistência de líderes - exceto "lideranças" informais de caráter organizativo - e, desse modo, pelo ensaio de uma cultura autonomista (CORRÊA, 2016) ou de uma espécie de temporalidade autônoma (NEGRI; HARDT, 2015). Por um lado, as ocupações funcionam como investida "momentânea" sobre o espaço escolar, prefigurando uma educação horizontal e autônoma, por outro, os coletivos e os movimentos se instauram com um pouco mais estabilidade nas escolas propondo, incessantemente, uma (re)educação que comporte, por exemplo, a diversidade de gêneros, de etnias, de orientações sexuais e que respeite a inclinação de alunas e alunos para organizar suas próprias atividades educativas.

As lutas estudantis com as quais nos encontramos desmentem as perspectivas anunciadas de que alunos e alunas em luta são vítimas de operações doutrinadoras da parte de seus professores e professoras. Antes, suas resistências se depararam com forte oposição do corpo escolar. Nas ocupações que visitamos, bem como nas práticas dos coletivos, foram várias as tentativas de desmobilização, crítica e difamação da parte do corpo docente e administrativo. Não encontramos indíciosde que as lutas em torno de temáticas feministas, raciais e LGBT, por exemplo, tenham partido de professores ou mesmo de discussões sobre tais temas feitas em sala de aula - em geral apontadas como inexistentes ou insuficientes. Em alguns casos, os professores e professoras que ensaiaram algum apoio a esses movimentos sofreram sanções administrativas, perderam seus empregos ou ficaram com um sentimento de exclusão e perseguição em seu ambiente de trabalho. Estamos, sem qualquer dúvida, diante de práticas resistentes amplamente autônomas e, em grande medida, contrárias às práticas pedagógicas dos colégios.

(C) ETD-Educação Temática Digital Campinas, SP v.19 n.esp $\quad$ p.75-95 jan./mar. 2017 
Enquanto as resistências secundaristas produzem cada vez mais experiências plurais e ensaiam um comum nas lutas, as relações de poder e as noções de propriedade que perpassam as instituições educacionais, em suas formas estatais ou privadas, parecem incapazes de captar a nova realidade, a saber: as lutas secundaristas formulam novos princípios de ampla relevância política e educacional. Para além da dualidade enrijecida entre o público e o privado e da polaridade, igualmente perniciosa, entre capitalismo e socialismo, um "tratado de alunalogia" vai sendo redigido, reivindicando um modelo de autogestão não apenas participativo, mas radicalmente democrático. São experiências empoderadoras e politicamente potentes que a governança representativa e as administrações escolares - mergulhada em suas próprias crises - tendem a ver como ameaça, baderna ou infantilidade, tamanho é o desafio que as resistências secundaristas apresentam.

A convocação da imagem da fênix feita pelo estudante "ocupado" na Escola Aristóbulo Barbosa Leãoexpressa uma potência para a transmutação. Rica em variações, a história do pássaro parece comportar ao menos duas constantes: a força para transportar cargas pesadas enquanto voa e o processo de renascimento pois, quando morre, entra em autocombustão, renascendo das próprias cinzas (BULFINCH, 2006). A fênix está presente no imaginário contemporâneo por suas aparições em grandes produções cinematográficas como, por exemplo, no escritório do bruxo Alvo Dumbledore, personagem da saga Harry Potter e no codinome da mutante Jean Grey, uma das heroínas mais poderosas entre os $X$ Men. A fênix encerra em si as três metamorfoses narradas por Friedrich Nietzsche (2007): como o espírito se torna camelo, como o camelo se torna leão e, finalmente, como o leão se torna criança.

O camelo é um animal transportador, é a "besta de carga" (NIETZSCHE, 2007, p. 40), sua função é carregar o peso dos valores estabelecidos e os fardos da educação, da moral e da cultura. O leão, por sua vez, é um destruidor, deseja liberdade, autonomia e, por isso, exerce "o direito sagrado de dizer não" (NIETZSCHE, 2007, p. 41), partindo as estátuas, pisoteando os fardos e dirigindo a crítica a todos os valores. Por fim, o leão transforma-se em criança para produzir um novo começo e criar novos valores, princípios e mundos. Há certo risco ao anunciarmos tão rapidamente essa fórmula de Nietzsche, mas não há exagero em afirmar que os e as secundaristas em luta não suportam mais carregar o fardo da escola e sua máquina produtora de corpos dóceis. Coletivos, ocupações e protestos secundaristas avançam contra e além das submissões escolares, não apenas para criticá-las por seus preconceitos, suas exclusões e sua incapacidade de produzir autonomia, mas também para reivindicar outras formas de estar junto, de inventar e aprender em comum. A fênix

(C) ETD-Educação Temática Digital Campinas, SP v.19 n.esp $\quad$ p.75-95 jan./mar. 2017 
secundarista não quer mais voar carregando o peso morto do aparelho escolar, por isso, sua morte em fogo vai sendo anunciada, aqui e ali, indicando o desejo pelo frescor de um novo começo.

Não há nada de necessário ou evolutivo na fórmula insinuada por Nietzsche. As resistências secundaristas permanecem em aberto e suas potências não estão livres de serem esmagadas por relações de poder que emergem no intuito de controlar as novas forças. No entanto, suspeitamos que uma outra escola e uma outra educação só são possíveis se experimentamos a escuta radical dos e das secundaristas e nos propomos a trabalhar e lutar "com" e "ao lado" deles e delas. Talvez a única conclusão possível venha na forma de uma coincidência feliz. Depois de quase três semanas sem retornar à universidade devido ao trabalho de apoio às ocupações, voltamos para uma aula. Na saída, já tarde da noite, passamos ao lado de uma reunião de universitários que ocupavam o prédio das Ciências Sociais e da Geografia. Observamos uma gatinha brincando no jardim e paramos para acariciá-la. Quando estávamos indo embora, uma ex-aluna, uma das primeiras participantes do coletivo Feminifes que estava na ocupação, nos chamou para um abraço apertado. Então, ela disse algo mais ou menos assim: "já conheceu nossa gatinha, né? 0 nome dela é Resistência".

\section{REFERÊNCIAS}

AGUIAR, Plínio. Campanha "Vai Ter Shortinhos Sim!" derruba proibição de "roupa curta” para meninas em escola de SP. Disponível em:<http://noticias.r7.com/saopaulo/campanha-vai-ter-shortinhos-sim-derruba-proibicao-de-roupa-curta-para-meninasem-escola-de-sp-08112015> Acesso em: 28 out. 2016.

BRASIL. Senado Federal. Projeto de Lei do Senado no 193, de 2016. Inclui entre as diretrizes e bases da educação nacional, de que trata a Lei no 9.394, de 20 de dezembro de 1996, o "Programa Escola sem Partido". Disponível em: $<$ http://www.senado.leg.br/atividade/rotinas/materia/getTexto.asp?t=192255\&c=PDF\&tp= 1. Acesso em: 16 out. 2016. Texto Original.

BULFINCH, Thomas. O livro de ouro da mitologia: histórias de deuses e heróis. Rio de Janeiro: Ediouro, 2006.

CAMPOS, Antonia J. M.; MEDEIROS, Jonas; RIBEIRO, Marcio M. Escolas de luta. São Paulo: Veneta, 2016.

(C) ETD-Educação Temática Digital Campinas, SP v.19 n.esp $\quad$ p.75-95 jan./mar. 2017 
CARVALHO, Alexandre Filordi de; CAMARGO, André Campos de. Guattari e a topografia da máquina escolar.ETD - Educação Temática Digital, Campinas, volume 17, no 1, jan./abr, 2015. Disponível em:

<http://periodicos.sbu.unicamp.br/ojs/index.php/etd/article/view/8634821> Acesso em: 07 out. 2016.

CHANGE.ORG. Vai ter shortinho sim. Disponível

em:<https://www.change.org/p/col\%C3\%A9gio-anchieta-vai-ter-shortinho-sim > Acesso em: 10 out. 2016.

CORRÊA, Murilo Duarte Costa. Escola contra o Estado. Disponível em:<http://uninomade.net/tenda/escola-contra-estado/>. Acesso em: 05 nov. 2016.

CAZÉ, Bárbara Maia Cerqueira. O uso e os atravessamentos do cineclube (e do cinema) na tessitura dos currículos em redes nos cotidianos. 2015. 126f. Dissertação (Mestrado em Educação). Programa de Pós-graduação em Educação, Universidade Federal do Espírito Santo. Vitória, ES. 2015.

CINECLUBE NOME PROVISÓRIO.Facebook. Disponível em:<https://www.facebook.com/cinenomeprovisorio/about/>. Acesso em:20 out. 2016.

DELEUZE, Gilles. Desejo e prazer. In: PELBART, Peter; ROLNIK, Suely (orgs.). Cadernos de Subjetividade. São Paulo: PUC-SP, v.1, n.1, 1993.

FEMINIFES. Facebook. Disponível em:<https://www.facebook.com/feminifes/about/> Acesso em: 02 nov. 2016.

FOUCAULT, Michel. História da Sexualidade I: a vontade de saber. Rio de Janeiro: Edições Graal, 2006.

FOUCAULT, Michel. Michel Foucault, uma Entrevista: Sexo, Poder e Política da Identidade. In: FOUCAULT, Michel. Ditos e escritos, volume IX: genealogia da ética, subjetividade e sexualidade. Rio de Janeiro: Forense Universitária, 2014. p. 251-265.

GALLO, Sílvio; FIGUEIREDO, Gláucia Maria. Entre maioridade e menoridade: as regiões de fronteira no cotidiano escolar. Aprender: cadernos de Filosofia e Psicologia da Educação, ano IX, no 14, jan./jun., 2015. Disponível em:<http://periodicos.uesb.br/index.php/aprender/article/viewFile/5299/5076> Acesso em: 13 out. 2016.

GUATTARI, Félix. Psicanálise e transversalidade. Aparecida: Ideias e Letras, 2004.

HARDT, Michael. The Commom in Communism. In: DOUZINAS, Costas; ZIZEK, Slavoj(Org.). The idea of communism. London / New York: Verso, 2010. p. 131-144.

(C) ETD-Educação Temática Digital Campinas, SP v.19 n.esp $\quad$ p.75-95 jan./mar. 2017 
HECKERT, Ana Lúcia Coelho. Narrativas de resistências: educação e política. 2014. $313 f$. Tese (Doutorado em Educação) - Programa de Pós-graduação em Educação. Universidade Federal Fluminense. Niterói, RJ. 2014.

JUNQUEIRA, Rogério Diniz. Heteronormatividade e vigilância de gênero no cotidiano escolar. In: RODRIGUES, Alexsandro; DALLAPICULA, Catarina; FERREIRA, Sérgio Rodrigo da Silva (orgs.). Transposições: lugares e fronteiras em sexualidade e educação. Vitória: EDUFES, 2014. p. 99-124.

KÓKA, Lucas Penteado. "O movimento secundarista é $100 \%$ horizontal", defende aluno que ocupou colégio em SP [01/06/16]. Entrevista concedida a Leandro Melito. Disponível em:<http://www.ebc.com.br/cidadania/2016/05/ocupacoes-nas-escolas-entenda-omovimento-estudantes-secundaristas > Acesso em: 09 out. 2016.

MENDES, Alexandre. Ocupações estudantis: novas assembleias constituintes diante da crise?2015. Disponível em: <http://uninomade.net/tenda/ocupacoes-estudantis-novasassembleias-constituintes-diante-da-crise-2/> Acesso em: 01 nov. 2016.

MOREIRA, Matheus. Secundaristas: anarquismo temporário contra governabilidade partidarista. 2015. Disponível em:

<http://www.revistaforum.com.br/diariodeestudante/2015/12/07/secundaristasanarquismo-temporario-contra-governabilidade-partidarista/> Acesso em: 13 out. 2016.

MOVIMENTO FALA BOCA - \#ocuparecreioimh. Facebook. Disponível em:<https://www.facebook.com/movimentofalaboca/about/> Acesso em: 22 out. 2016

NEGRI, Antonio; HARDT, Michael. Declaração - Isso não é um manifesto. São Paulo: n-1 edições, 2014.

Bem-estar comum. Rio de Janeiro: Record, 2016.

NIETZSCHE, Friedrich. Assim falava Zaratustra: um livro para todos e para ninguém. Petrópolis: Vozes, 2007.

O GLOBO. Colégio Pedro II extingue distinção de uniforme por gênero. Disponível em:<http://oglobo.globo.com/sociedade/educacao/colegio-pedro-ii-extingue-distincao-deuniforme-por-genero-20139240>. Acesso em: 07 out. 2016.

OCUPA IRMÃ MARIA HORTA.Facebook Disponível em:<https://www.facebook.com/OCUPAIMH/posts/1782163445332612>. Acesso em: 05 nov.2016.

(C) ETD-Educação Temática Digital Campinas, SP v.19 n.esp $\quad$ p.75-95 jan./mar. 2017 
OLIVEIRA, Hanna; PUERTA, Sara. A revolução será secundarista. Disponível em:<http://www.ueesp.org.br/noticia/295/a-revolucao-sera--secundarista.html> Acesso em: 03 out. 2016.

ORTELLADO, Pablo. A primeira flor de junho. In: CAMPOS, Antonia J. M; MEDEIROS, Jonas; RIBEIRO, Marcio M. Escolas de luta. São Paulo: Veneta, 2016.

PELBART, Peter Pál. Tudo o que muda com os secundaristas. Outras Palavras: comunicação compartilhada e pós-capitalismo. 2016. Disponível em:

<http://outraspalavras.net/brasil/pelbart-tudo-o-que-muda-com-os-secundaristas/> Acesso em: 09 out. 2016.

REVEL, Judith. Resistências, subjetividades, o comum. Lugar Comum,- Vol 1, n.ㅇ 35-36 - out. 2012. Disponível em:<http://uninomade.net/wp-

content/files_mf/110210120912Resist\%C3\%AAncias\%20subjetividades\%20o\%20comum\%2 0-\%20Judith\%20Revel.pdf> Acesso em: 12 out. 2016.

RODRIGUES, Alexsandro; ALVIM, Davis Moreira. Como cartografar resistências?

Apontamentos sobre contradispositivo e criação.Lugar Comum,- Vol 1, n. 48 - jun 2016 -

ago 2016. Disponível em:<http://uninomade.net/wp-

content/files_mf/147097436400Como\%20cartografar\%20resist\%C3\%AAncias,\%20apontam entos\%20sobre\%20contradispositivo\%20e\%20cria\%C3\%A7\%C3\%A30\%20-

\%20Alexsandro\%20Rodrigues\%20e\%20Davis\%20Moreira\%20Alvim.pdf>Acesso em: 17 out. 2016.

UNIÃO BRASILEIRA DOS ESTUDANTES SECUNDARISTAS (UBES). Primavera secundarista: a luta de quem ocupa as escolas. Disponível em:<http://ubes.org.br/2016/primaverasecundarista-a-luta-de-quem-ocupa-as-escolas-do-brasil/> Acesso em: 09/10/2016.

VAI TER SHORTINHOS SIM.Facebook. Disponível em: <https://www.facebook.com/Vai-tershortinhos-sim-579551658849480/?fref=ts>. Acesso em: 14 set. 2016.

VASCONCELLOS, Hygino. Alunos usam shorts femininos em apoio às meninas em escola do RS. Disponível em: <http://g1.globo.com/rs/rio-grande-do-sul/noticia/2016/02/alunosusam-shorts-femininos-em-apoio-meninas-em-escola-do-rs.html> Acesso em: 28 out. 2016.

YOUTUBE. Escola sem Opressão. Movimento Fala Boca. Disponível em:<https://www.youtube.com/watch?v=EAla2K-LU6k>. Acesso em: 05 out. 2016.

(C) ETD-Educação Temática Digital Campinas, SP v.19 n.esp $\quad$ p.75-95 jan./mar. 2017 


\section{Agradecimentos}

Somos imensamente gratos aos movimentos Fala Boca, Icacheou e Vai ter shortinho, sim!, aos coletivos Cineclube Nome Provisório, Colorifes, Feminifes e Melanina e aos e às secundaristas "ocupados/as" nas escolas Aristóbulo Barbosa Leão, Irmã Maria Horta e Maria Ortiz pelas conversas, pelo aprendizado, pela afetividade e pela atenção dispensados; além, é claro, dos cafés, do macarrão com salsicha, das risadas e das dores compartilhados. Vocês são beleza singular, coragem infinita e potência para a luta. Nãonos nos esqueceremos desse sopro de vida que nos foi proporcionado.

'A revisão gramática do texto por: Priscila Queiroz e WilberthClaython Ferreira Salgueiro.

(C) ETD- Educação Temática Digital Campinas, SP v.19 n.esp $\quad$ p. 75-95 jan./mar. 2017 